\title{
Good things better? Reappraisal and discrete emotions in Acquired Brain
} Injury

Rowlands, Leanne; Coetzer, Bernardus; Turnbull, Oliver

\section{Neuropsychological Rehabilitation}

DOI:

10.1080/09602011.2019.1620788

Published: 25/11/2020

Peer reviewed version

Cyswllt i'r cyhoeddiad / Link to publication

Dyfyniad o'r fersiwn a gyhoeddwyd / Citation for published version (APA):

Rowlands, L., Coetzer, B., \& Turnbull, O. (2020). Good things better? Reappraisal and discrete emotions in Acquired Brain Injury. Neuropsychological Rehabilitation, 30(10), 1947-1975. https://doi.org/10.1080/09602011.2019.1620788

\footnotetext{
Hawliau Cyffredinol / General rights

Copyright and moral rights for the publications made accessible in the public portal are retained by the authors and/or other copyright owners and it is a condition of accessing publications that users recognise and abide by the legal requirements associated with these rights.

- Users may download and print one copy of any publication from the public portal for the purpose of private study or research.

- You may not further distribute the material or use it for any profit-making activity or commercial gain

- You may freely distribute the URL identifying the publication in the public portal ?
}

Take down policy

If you believe that this document breaches copyright please contact us providing details, and we will remove access to the work immediately and investigate your claim. 
Reappraisal and discrete emotions in ABI

\section{Good things better? Reappraisal and discrete emotions in Acquired Brain Injury}

Leanne Rowlands $^{12}$, Rudi Coetzer ${ }^{12}$, \& Oliver H. Turnbull ${ }^{1}$

School of Psychology, Bangor University, Bangor, U.K. ${ }^{1}$

The North Wales Brain Injury Service, Betsi Cadwaladr University Health Board, Colwyn

$$
\text { Bay, U.K. }{ }^{2}
$$

Corresponding Author: Leanne Rowlands

leanne.rowlands@bangor.ac.uk

https://orcid.org/0000-0003-1130-5072

@LeanneRowlands0 (twitter) 


\begin{abstract}
There has been substantial interest in emotion after acquired brain injury (ABI), but less attention paid to emotion regulation (ER). Research has focused primarily on the ER strategy of reappraisal for regulating negative emotions, without distinguishing between classes of emotion, and there has been no attempt at exploring these differences in patients with ABI. The present study explored components of reappraisal, across classes of emotion, and their associated neuropsychological mechanisms. Thirty-five patients with ABI and twenty-two matched healthy control participants (HCs) completed two questionnaires, a battery of cognitive tasks, and an emotion regulation task (the Affective Story Recall Reappraisal task). Results suggest that those with $\mathrm{ABI}$ take longer, and generate fewer reappraisals than HCs across several discrete emotions. Notably, their ability to decrease emotional intensity did not differ significantly to HCs for negative emotions, but findings suggest that their reappraisals are less effective when up-regulating neutral emotions to positive. Working memory was the only significant predictor of the total number of reappraisals generated, and the time taken to produce a first reappraisal. Implications of these findings are discussed in the context of neuropsychological rehabilitation, including the role of the relatives in implementing and reinforcing micro-interventions.
\end{abstract}

Keywords: emotion regulation, reappraisal, acquired brain injury, discrete emotions, cognitive control

Word count: 6819 
Reappraisal and discrete emotions in ABI

Emotional changes have long been recognized as common impairments following acquired brain injury (ABI) (Draper \& Ponsford, 2009; Diaz, Schwarzbold, Thais, Hohl, et al., 2012; Gainotti, 1993), and there has been substantial interest in emotion after ABI (Alway, McKay, Ponsford, \& Schönberger, 2012; Shields, Ownsworth, O’Donovan, \& Fleming, 2016; Williams \& Evans, 2003). A number of studies that have investigated the effects of injury on, for example, emotion perception (Bornhofen \& McDonald, 2008), recognition (Calder, Keane, Manes, Antoun \& Young, 2000) and experience (Calder et al., 2000; de Sousa, McDonald, \& Rushby, 2012). Indeed, this is in line with the emergence of a growing field of affective neuropsychology (McDonald, 2017).

One aspect that has received less attention, but is particularly important to consider, is emotion regulation (ER) (Bechara, 2004; Beer \& Lombardo, 2007). The most extensively used approach to ER is the "Process model", which describes this ability as a range of strategies that influence emotions, their intensity and the way they are experienced and expressed (Gross, 2013, 2014, 2015; Gross \& Muñoz, 1995). Impairment in ER is a common consequence of ABI, across various pathologies and brain regions (Bechara, 2004; Beer \& Lombardo, 2007), and is a key transdiagnostic element of global distress and mood disorders in this population (Shields et al., 2016).

The "Process model" of ER outlines five classes of strategy that are used to regulate emotions (Gross, 2014). One particular approach, reappraisal, is the most frequently investigated (Goldin, McRae, Ramel, \& Gross, 2008; Troy, Shallcross, Brunner, Friedman, \& Jones, 2018; Zilverstand, Parvaz, \& Goldstein, 2017), and involves changing the meaning of a situation, to alter its emotional consequence (Gross, 2002; McRae, Ciesielki, \& Gross, 2012b). Reappraisal is well-understood to be an effective method for managing feelings (Sheppes \& Meiran, 2007; Troy, Wihelm, Shallcross, \& Mauss, 2010). Its use is positively 
Reappraisal and discrete emotions in ABI

correlated with well-being and greater psychological health in neurologically healthy individuals (Gross \& John, 2003; McRae, Jacobs, Ray, John, \& Gross, 2012).

\section{Reappraisal and Cognitive Control}

Reappraisal is also known to be dependent on several cognitive control processes (Ochsner \& Gross, 2005). This idea is consistent with neuroimaging studies, which have identified activation in areas in the prefrontal cortex (PFC) supporting cognitive control (Buhle, Silvers, Wager, Lopez, et al., 2014; Kalisch, 2009; McRae, Hughes, Chopra, Gabrieli, et al., 2010). Researchers have also tried to identify which neuropsychological functions support this complex process (McRae et al., 2012); for example, in the neurologically healthy, working memory may be a key capacity to keep the first appraisal in mind (Hendricks \& Buchanan, 2015; McRae et al., 2012; Schmeichel, Volokhov, \& Demaree, 2008). However, research into the neuropsychological mechanisms of reappraisal has produced variable evidence (Hendricks \& Buchanan, 2016; McRae et al., 2012; Salas et al., 2014). In part because participants' reappraisals cannot (because of movement artefacts) be verbally produced in an imaging setting (e.g. Buhle et al., 2014). Additionally, these studies are in neurologically normal participants who retain this ability.

To address these critical gaps, Salas and colleagues (2014) investigated reappraisal generation in patients with brain injury, comprising reappraisal productivity (number of reappraisals generated), and difficulty (time to generate first reappraisal). This has been a fruitful approach because patients with ABI are often impaired in the manipulation of thought (Gomez Beldarrain, Garcia-Monco, Astigarraga, Gonzalez, \& Grafman, 2005; Luria, 1966), and therefore may struggle to generate positive re-interpretations (Salas et al., 2014). Braininjured patients may be especially vulnerable to reappraisal deficits in the presence of time limitations, related to inhibition and verbal ability performance, but not working memory 
Reappraisal and discrete emotions in ABI

(Salas et al., 2014). Notably, this is a contrasting finding to the earlier literature in neurotypical participants, who are able to generate reappraisals (e.g. McRae et al., 2012).

\section{Discrete Emotions}

Research on ER, and its biological substrate, has focused primarily on reappraisal for negative emotions (e.g. Goldin et al., 2008), often not distinguishing between discrete negative emotions. Additionally, traditional reappraisal paradigms typically use visual stimuli (from the International Affective picture System, IAPS, Lang, Bradley, \& Cuthbert, 1997) which may trigger diverse discrete emotions, but these emotional reactions are only assessed in terms of valence and intensity. This is noteworthy because different classes of emotion contain unique information about the interaction with the environment, and enable adaptive responding (Ekman, 1992; Lazarus \& Smith, 1988; Mauss, Levenson, Wilhelm, McCarter, \& Gross, 2005). Equally important, these discrete emotions are supported by different neural systems (Celeghin, Diano, Bagnis, Viola, \& Tamietto; 2017; Panksepp, 2003; 2004; 2005; 2011, Vytal \& Hamann, 2010), with a large neuroimaging literature supporting interacting brain regions associated with the experience, perception and recognition of various categories of emotion (Adolphs 2002; Lindquist, Wager, Kober, Bliss-Moreau, \& Barrett, 2012, for a meta-analysis).

The identification of multiple classes of emotion has provided an opportunity to understand how such experiences might vary. Some discrete emotions have been more closely associated with differences in decision-making (Lerner \& Keltner, 2001), perception of risk (Lench \& Levine, 2005), and behaviour (See Lench, Flores, \& Bench, 2011 for a meta-analysis). The majority of research on emotion regulation has yet to systematically compare strategies using a discrete emotion framework, instead viewing ER as a global ability across emotions (e.g. Gratz \& Roemer, 2004; Gross \& John, 2003). There is, however, a modest body of work describing how ER, and specifically reappraisal, varies across 
Reappraisal and discrete emotions in ABI

positive and negative emotions (Kim \& Hamann, 2007; Mak, Hu, Zhang, Xiao, \& Lee, 2009; Nezlek \& Kuppens, 2008), suggesting that neurologically healthy individuals find it easier to up-regulate positive emotions through reappraisal, than down-regulating negative emotions (Kim \& Hamann, 2007). Some of the most convincing evidence of the relevance of discrete emotions in ER comes from the finding that strategies employed to regulate anger and sadness differ in both their use and effectiveness (Rivers, Brackett, Katulak, \& Salovey, 2007). Individuals are more likely to use reappraisal for sadness than anger, and more likely to use situation-based strategies for anger compared to sadness (Rivers et al., 2007). It is, however, less clear how people with brain injury use ER strategies across different emotions.

\section{Discrete Emotions in ABI Research}

In $\mathrm{ABI}$, there is a large body of research exploring various aspects of emotional difficulties (e.g. Shields et al., 2016; Williams \& Evans, 2003). This includes a prominent theory that the right hemisphere mediates and processes negative emotions, and the left hemisphere positive emotions (the valence hypothesis) (Davidson, 2001; Demaree, Everhart, Youngstrom, \& Harrison, 2005). Though studies on the valence hypothesis have provided mixed support (Demaree et al., 2005, for a review), there is substantial evidence of right hemisphere dominance for emotional processing regardless of valence (the right hemisphere hypothesis) (Gainotti, 2005, 2012, for reviews).

Additionally, there are a number of investigations of difficulties with discrete negative emotions, in particular anger (Mcdonald, Hunt, Henry, Dimoska, \& Bornhofen, 2010; Neumann, Malec, \& Hammond, 2015), depression (Kreutzer, Seel, \& Gourley, 2001), and a range of emotional disorders (Shields et al., 2016). There are also studies which systematically address emotional processes across various emotion categories, for example the study of emotion recognition across classes of emotions after TBI (Babbage, Zupan, Neumann, Tomita, \& Willer, 2011; Croker \& McDonald, 2005), the re-experience of discrete 
Reappraisal and discrete emotions in ABI

emotions in Korsakoff patients (Stanciu, Rafal, \& Turnbull, 2018), and emotional experience in patients with ABI (Salas, Radovic, Castro, \& Turnbull, 2015).

\section{The present study}

To our knowledge, there has been no attempt at exploring differences in emotion regulation (based upon the "Process model") across different classes of emotions, in patients with ABI and healthy controls (HC). This provides an opportunity to understand how a wellresearched ER strategy, reappraisal, might differ across emotions following injury. Building on previous research, the present study employed an internal mood induction paradigm (Salas, Radovic, \& Turnbull, 2012: Salas et al., 2015) adapted to measure reappraisal. Notably, personally-salient emotion elicitation tasks, such as the Affective Story Recall task (ASR) (Turnbull, Evans, \& Owen, 2005), may be more effective at inducing specific discrete emotions, at greater intensities, compared to external emotion elicitation (Salas et al., 2012, 2015).

The present study is the first to investigate reappraisal in ABI patients using an autobiographical recall reappraisal task (c.f. Salas et al., 2015, which focused on emotion elicitation). In addition to reappraisal ability, the present study also examined reappraisal generation, by measuring productivity (total number of reappraisals generated) and difficulty (time taken to reappraise), as based on previous reappraisal research in this patient sample (Salas et al., 2014).

Given that patients with $\mathrm{ABI}$ experience difficulties across a range of discrete emotions, the following hypotheses are explored. Firstly, a "discrete emotion hypothesis": that patients with ABI will take longer to generate reappraisals (reappraisal difficulty), will produce fewer reappraisals (reappraisal productivity), and have less effective reappraisals (reappraisal ability) compared to the HC group, differentially across classes of emotions. In addition, a "cognitive control hypothesis": cognitive control abilities (working memory, 
Reappraisal and discrete emotions in ABI

inhibition, and verbal ability) will be positively related to reappraisal productivity and ability, and negatively related to reappraisal difficulty.

\section{Methods}

\section{Participants}

A total of 57 participants were included in the study, comprising an ABI group, and an age and education matched $\mathrm{HC}$ group.

\section{Acquired Brain Injury Group}

Thirty-five participants with acquired brain injury (ABI) were prospectively referred mainly by clinicians at the North Wales Brain Injury Service (NWBIS), Betsi Cadwaladr University Health Board (BCUHB), a community-based outpatient rehabilitation service $(n=$ 25). A small proportion were recruited from a social rehabilitation day service in Manchester (The Headforward Centre) $(n=5)$, and through North Wales branches of the brain injury charity, Headway $(n=5)$. Eligible participants were adults with a confirmed ABI, as per NWBIS referral criteria (Coetzer, Vaughan, Roberts, \& Rafal, 2003), duration of 9 months or greater since injury, and sufficient cognitive and language ability to complete the tasks (as judged by clinicians and staff members). Exclusion criteria included the presence of a psychiatric or substance use disorder in need of acute care, a neurodegenerative condition, or learning disability. Participants were also excluded if they did not have the capacity to give informed consent.

The average age of participants was $51(S D=11.82$, range $26-74)$, with an average of 13 years in education $(S D=2.24$, range $10-18)$. There were 27 males and 7 females, with an average time since injury of 8.7 years ( $S D=9.86$, range 9 months - 32 years). Details of injury characteristics can be found in Table $\mathbf{1}$.

Healthy Control Group 
Reappraisal and discrete emotions in ABI

Twenty-two, age and education matched, neurotypical healthy control participants were recruited from the North Wales community. The average age of participants was 54 $(S D=8.46$, range $35-69)$, with an average of 12.5 years in education $(S D=1.79$, range 10 16). There were 12 males and 10 females.

\section{[Table 1 here]}

\section{Measures}

\section{Emotional assessment}

In order to evaluate emotional symptomology and functioning, two self-report questionnaires were employed. Firstly, the Hospital Anxiety and Depression Scale (HADS) (Zigmond \& Snaith, 1983) was administered. This consists of anxiety and depression subscales, with 14 items such as 'I feel tense or wound up'. The participant indicates, on a 4 point scale, agreement with each statement. This is a reliable and valid measure of anxiety and depression (Zigmond \& Snaith, 1983), and its use has been validated in individuals with brain injury (Schönberger \& Ponsford, 2010). Secondly, the Emotion Regulation Questionnaire, adapted for children and adolescents (ERQ-CA) (Gullone \& Taffe, 2012), to assess self-report reappraisal in daily life. The adapted version was used because feedback from previous work in our lab (Salas et al., 2014) using the original ERQ (Gross \& John, 2003), suggested that several patients struggled to grasp the wording. The ERQ-CA reports sound internal consistency (Gullone \& Taffe, 2012).

\section{Cognitive control assessment}

A short battery of cognitive control tasks was used to measure working memory, verbal fluency, and inhibition.

a) Working Memory was measured using the Digit Span (forward, backwards, and sequence) sub-task from the Wechsler Adult Intelligence Scale (WAIS IV) (Wechsler, 2008). These tasks are informative measures of working memory in brain-injured 
participants, and have been used as a marker for cognitive deficits (e.g. Millis, Rosenthal, Novack, Sherer, et al., 2001).

b) Verbal Ability was assessed using the Letter Fluency sub-task from the Delis-Kaplan Executive Function system (D-KEFS) (Delis, Kaplan, \& Kramer, 2001). Letter fluency has been shown to be more strongly associated to cognitive control than other measures (Henry \& Crawford, 2004), and has been used previously to investigate cognitive control and reappraisal in patients with ABI (Salas et al., 2014).

c) Inhibition was evaluated using the Hayling sentence completion task from the Hayling and Brixton tests (Burgess \& Shallice, 1997). This task was chosen due to its sensitivity (Burgess \& Shallice, 1997), and validity in a sample of brain-injured patients (Odhuba, van den Broek, \& Johns, 2005).

\section{Affective Story Recall Reappraisal (ASRR) task}

This task has been adapted from previous reappraisal generation tasks that have used stimuli form the IAPS (Salas, Gross, Rafal, Viñas-Guasch, \& turnbull, 2013; Salas et al., 2014), and the ASR emotion elicitation task, described in detail elsewhere (Salas et al., 2012; Turnbull et al., 2005). Recalled personal events, as opposed to traditional IAPS stimuli, may elicit discrete target emotions at higher intensities (Chirico, Cipresso, \& Gaggioli, 2018) and follow an emerging trend in emotion research of focusing on naturalistic contexts (Siedlecka \& Denson, 2018).

The task (See Appendix A for details) was carried out on a 13" laptop screen, providing step-by-step instructions, to avoid any memory bias. Following 2 practice trials, the participant was shown an emotion word (either 'sad', 'scared', 'angry', or 'neutral'), and described an event which caused them to feel that emotion. Following this they indicated how intense they felt the emotion on a 0 to 10 scale, before generating reappraisals, and associated intensity measurement. 
Reappraisal and discrete emotions in ABI

The 3 negative emotions (sadness, fear, and anger) were chosen because of widespread agreement in the literature that these are basic emotions (Tracy \& Randles, 2011, for a review). The 'neutral' condition involved neutral recollections, to be reappraised into positive emotions; chosen to map on to reappraisal in real life settings (e.g. Livingstone \& Srivastava, 2012). ${ }^{1}$ Each emotion word appeared twice, resulting in 8 total trials. The task was recorded and transcribed verbatim, the total number of reappraisals were counted, and the time to generate a first reappraisal noted.

See Figure 1 for visual representation of one trial ("sad" condition).

[Figure 1 here]

\section{Procedure}

Ethical approval was granted by Bangor University (2017-16048) and BCUHB (224613). For the ABI group, potential participants were identified prospectively by members of the clinical team at the NWBIS, rehabilitation staff at the Headforward Centre, and the Chairs of Headway branches. One referred participant was not included, due to later concerns of a neurodegenerative condition. Healthy control participants (HC) recruited form the community were invited to take part. Following written informed consent, neuropsychological and emotional tasks were carried out within one session in a quiet room: at Bangor University, NWBIS, Headforward Centre, or participants' own homes.

Questionnaires, neuropsychological tasks, and the ASRR task were administered in random order, with a short-break approximately half-way through the session. The ASRR task was transcribed and reappraisals were counted. If needed, a reappraisal coding guide was used in support (McRae et al., 2012b). All measures were administered by the first author, or trained research assistants.

\footnotetext{
${ }^{1}$ The alternative, making positive emotions more positive, would effectively be promoting unrealistic optimism (Fleming \& Strong, 1995). It would also be difficult to measure any differences in emotional intensity because of ceiling effects.
} 
Reappraisal and discrete emotions in ABI

\section{Data Analysis}

Three measures of reappraisal were produced by the ASRR task, resulting in three variables. Reappraisal difficulty was obtained by averaging the time it takes to produce a first reappraisal. Reappraisal productivity was calculated by adding the total number of reappraisals produced, and reappraisal ability was calculated by averaging the difference value between self-report emotional intensity before, and after, reappraising.

Data was analysed using 'R' Software, with additional packages ('Stats', 'Complmrob', and 'robustbase'). As the data was not normally distributed the discrete emotion hypothesis was analysed with several Mann-Whitney U tests, with Bonferroni adjustment for multiple comparisons (new alpha level .013), comparing 1) reappraisal difficulty, 2) reappraisal productivity, and 3) reappraisal ability, between patients with ABI and the HC group across the neutral, sadness, fear, and anger conditions.

The cognitive control hypothesis was explored by carrying out three separate robust multiple linear regression analyses using the 'Imrob' function ('robustbase' package) with bootsrapped coefficients using fast and robust bootsrap via the 'bootscoef' function ('complmrob’ package) with 'MM' method (Salibián-Barrera, Aelst, \& Willems, 2008). Inhibition (Hayling sentences task scores), working memory (Digit Span WMS IV scores), and verbal ability (Letter fluency DKEFS scores) were entered as predictors, with the outcome variable consisting of reappraisal difficulty, productivity, and ability across all emotion trials combined (ASRR Total). Bootstrapping techniques were employed for 999 bootstrap samples as a form of model validation (Babyak, 2004; Efron, 2003).

\section{Results}

\section{Emotional and Cognitive functioning}

Participants' average scores on measures of emotional and cognitive functioning can be seen in Table 2. In relation to depression symptomology, participants with ABI scored on 
Reappraisal and discrete emotions in ABI

average within the "borderline abnormal" range on the HADS, and were significantly more depressed than the HC group, with 11/35 scoring within the clinical range. On the anxiety subscale, participants with ABI also scored on average within the "borderline abnormal" range and were significantly more anxious than the HC group, with 20/35 in the clinical range. Participants with ABI also reported using reappraisal significantly less frequently to regulate their emotions than the $\mathrm{HC}$ group on the ERQ-CA.

On average both $\mathrm{ABI}$ and $\mathrm{HC}$ group scored within the "moderate average" range on the Hayling sentence task, as an indicator of inhibition. Working memory scores (Digit span, WAIS IV) and verbal ability scores (Letter fluency, DKEFS) for the ABI group were in the "low average" range, and were significantly less than the HC group.

[Table 2 here]

\section{The Discrete Emotion Hypothesis}

This sought to investigate reappraisal difficulty, productivity, and ability across 4 classes of emotion.

\section{Reappraisal Difficulty}

The average time taken to produce a first reappraisal (reappraisal difficulty) was compared between the ABI and HC group, across the emotion classes (neutral, sadness, fear, and anger). See Table 3 for descriptive statistics.

\section{[Table 3 here]}

Results of the Mann-Whitney U test demonstrates that the ABI group took significantly more time to produce a reappraisal compared to the HC group for the neutral ( $U$ $=150.00, z=-3.86, p<.001, r=.51)$, sadness $(U=193.50, z=-3.14, p=.001, r=.42)$, and fear conditions $(U=145.50, z=-3.94, p<.001, r=.52)$, all demonstrating medium-to-large effect sizes. There was no significant difference between groups for the anger condition, although there was a trend $(U=275.50, z=-1.80, p=.072, r=.24)$. See Figure 2 . 
Reappraisal and discrete emotions in ABI

[Figure 2 here]

Reappraisal Productivity

The total number of reappraisals produced (reappraisal productivity) was compared between the ABI and HC group, across the emotion classes. See Table 4 for descriptive statistics.

[Table 4 here]

Results of the Mann-Whitney U test demonstrated that the ABI group produced significantly fewer reappraisals compared to the HC group for the neutral $(U=222.50, z=-$ 2.753, $p=.005, r=.36)$, sadness $(U=232.00, z=-2.55, p=.010, r=.34)$, and fear conditions $(U=210.00, z=-2.92, p=.003, r=.39)$, all demonstrating medium effect sizes. The difference between groups for the anger condition was marginally significant (with the adjusted alpha level), and demonstrated a medium effect size $(U=243.50, z=-2.26, p=$ $.018, r=.31$ ). See Figure 3 .

[Figure 3 here]

\section{Reappraisal Ability}

This analysis was conducted to investigate differences is reappraisal ability between the ABI and HC group across classes of emotion. Participants' reappraisal ability scores (difference between initial self-report arousal and arousal after reappraising) were compared across emotions: neutral, sadness, fear, and anger. For descriptive statistics see Table 5.

\section{[Table 5 here]}

The results of the Mann-Whitney $U$ test indicated that the ABI group had significantly lower reappraisal ability scores, compared to the $\mathrm{HC}$ group, on the neutral condition with a medium effect size $(U=188.00, z=-3.265, p=.001, r=.43)$. There were no significant differences in reappraisal ability across the sadness $(U=284.50, z=-1.65, p=.099, r=.22)$, 
Reappraisal and discrete emotions in ABI

fear $(U=311.50, z=-1.21, p=.230, r=.16)$, and anger conditions $(U=266.500, z=-1.938$, $p=.053, r=.26)$. See Figure $4 .^{2}$

[Figure 4 here]

\section{The Cognitive Control Hypothesis}

This sought to investigate a range of cognitive elements related to the components of reappraisal. A series of robust multiple linear regression analyses were conducted to investigate the relationship between three measures of cognitive control (working memory, verbal ability, and inhibition) and reappraisal components (difficulty, productivity, and ability) across all emotion trials combined (ASRR Total). For this the ABI group and HC group were combined to increase sample size.

Reappraisal difficulty. The model explained $25 \%$ of the variance, and significantly improved prediction of reappraisal difficulty $\left(\mathrm{R}^{2}=.25, F(3,53)=17.40, p<.001\right)$. According to bootstrap for coefficients, the only significant predictor was working memory (Digits WAIS scores) $(\beta=-.22, p=.006)$, suggesting that a unit increase in working memory ability would result in a decrease of 0.22 seconds in the time taken to generate a first reappraisal.

Reappraisal productivity. The model containing all predictor variables (working memory, verbal fluency, and inhibition) explained $21 \%$ of the variance, and significantly improved prediction of reappraisal productivity $\left(\mathrm{R}^{2}=.21, F(3,53)=18.41, p<.001\right)$. Bootstrap for coefficients, demonstrated that the only significant predictor in the model was working memory (Digits WAIS scores), $\beta=.54, p=.001$. The coefficients demonstrate that a unit increase in working memory would result in an 0.54 increase in the number of reappraisals produced.

\footnotetext{
${ }^{2}$ Given the distributed nature of lesion site and underlying pathology of the sample, Mann Whitney U tests were carried out to compare reappraisal difficulty, productivity, and ability across all emotions; between those with TBI $(n=20)$ vs CVA $(n=13)$, and those with frontal brain injury $(n=13)$ vs non-frontal injury $(n=6)$. There were no significant differences or obvious trends. A Kruskal-Wallis test was used to compare the components of reappraisal across emotions between those with left lateralised $(n=7)$, right lateralised $(n=7)$, and bilateral lesions $(n=9)$. Again, there were no significant differences or obvious trends.
} 
Reappraisal ability. The model explained only $2 \%$ of the variance in reappraisal ability, and did not significantly improve predictions $\left(\mathrm{R}^{2}=.02, F(3,53)=1.37, p=.712\right)$. There were no significant predictors within the model. ${ }^{3}$

\section{Summary of results}

These findings suggest that, compared to $\mathrm{HC}$ participants, patients with $\mathrm{ABI}$ take longer to generate a reappraisal, and generate fewer reappraisals across all emotion conditions. Concerning reappraisal ability, this might vary as a function of the emotion type, with the results suggesting that participants with $\mathrm{ABI}$ are comparatively less effective at upregulating neutral to positive emotion, compared to the down-regulation of sadness, fear, and anger. In regards cognitive control hypothesis, the findings suggested that working memory has a role in two subprocesses of reappraisal only: predicting the time taken to produce a reappraisal (reappraisal difficulty), and the total number of reappraisals produced (reappraisal productivity). There were, however, no predictors of reappraisal ability, suggesting that cognitive control may not play a role in regulating emotional experience through reappraisal.

\section{Discussion}

There has been no previous attempt to systematically compare components of reappraisal, using a discrete emotion framework, in an ABI sample. This is an important question, in particular in the context of brain-injured patients, where it might inform rehabilitation clinicians. Additionally, the research into the underlying neuropsychological components has not been especially clear (Hendricks \& Buchanan, 2016; McRae et al., 2012). The present study aimed to address these gaps, by investigating whether components of reappraisal (difficulty, productivity, and ability) varied as a function of the emotion in

\footnotetext{
${ }^{3}$ Due to the differences in reappraisal ability between the negative emotions and the neutral emotion, reported in the discrete emotion hypothesis, a total score of negative emotions only (excluding neutral) was calculated and the regression run again. The results remained similar, with low explanation of variance $(6 \%)$ and no significant predictors in the model.
} 
patients with $\mathrm{ABI}$ relative to a $\mathrm{HC}$ group. A second aim was to investigate the cognitive control capacities related to these three components of reappraisal.

\section{Reappraisal generation across discrete emotions}

A key finding of the present study was that patients with brain injury took significantly longer to generate a reappraisal (compared to HC participants) for the sadness, fear, and the neutral to positive conditions. They also took longer for the anger condition, though this did not reach significance (perhaps an artefact of the small sample size). This provides further support for Salas and colleagues (2014), who found that patients with ABI may be vulnerable to reappraisal generation impairment in the presence of time limitations. Additionally, the present study extends this idea by suggesting that a brain injury compromises the capacity to positively re-interpret events quickly across several discrete emotion categories. In other words, it seems that this impairment is a global difficulty, and not related to any specific emotions.

The results also demonstrate that those with ABI generated significantly fewer reappraisals relative to the $\mathrm{HC}$ group, across the sadness, fear and the neutral-to-positive conditions, and approached significance for the anger condition. This is a contrasting finding to the only previous group study of reappraisal generation in an ABI sample, which demonstrated that participants with brain injury were able to generate a similar number of reappraisals to HCs (Salas et al., 2014). This variation may be a result of tasks used (traditional IAPS paradigm versus a task based on personally salient emotional memories).

This is consistent with the idea that reappraisal impairment may be exaggerated in situations that are closer to real life (Salas et al., 2014).

Considered together, it seems that those with an $\mathrm{ABI}$ are less able to generate reappraisals, across several emotions. If reappraisal is a two-stage process (initial meanings are inhibited, and new meanings generated) (Salas et al., 2014), the findings suggest that the 
Reappraisal and discrete emotions in ABI

presence of a brain injury particularly impacts upon this first stage. A possible explanation is that this particular ER strategy relies on the core ability to think flexibly, in order to generate new interpretations of events (Ochsner \& Gross, 2004), something that is known to be affected in this patient group (Gomez Beldarrain, et al., 2005). Reappraisal is complex, and dependent upon cognitive control processes (McRae et al., 2012; Ochsner \& Gross, 2005), therefore it is not surprising that patients with $\mathrm{ABI}$ who are executively impaired find it more difficult to generate reappraisals. This idea is consistent with a recent line of evidence in older adults, which suggests that reappraisal may not be the ER strategy of choice for those with age-related cognitive decline (Scheibe, Sheppes, \& Staudinger, 2015).

\section{Reappraisal ability across negative emotions}

To our knowledge the present study is the first to investigate reappraisal ability, defined as the reappraisals' success at reducing (or amplifying) emotional intensity in line with the reappraisals' goals, in a group of patients with brain injury. There were no significant differences in reappraisal ability between $\mathrm{HCs}$ and patients with $\mathrm{ABI}$ when regulating sadness, fear, or anger, although slightly lower for the ABI group. Overall, this suggests that once they are able to generate reappraisals, patients with brain injury are equally able to reduce the intensity of negative emotions through using this ER strategy. This has important implications for neurorehabilitation (See more below).

The present study suggests that all negative emotions are reappraised similarly for both the $\mathrm{ABI}$ and $\mathrm{HC}$ group, comparable to that reported elsewhere in the discrete emotion literature in neurologically healthy adults (Mikolajczak, Nelis, Hansenne, \& Quoidbach, 2008). The study also extends previous findings in work with children, which demonstrated that reappraisal is an effective strategy for regulating both fear and sadness (Davis, QuiñonesCamacho, \& Buss, 2016). It is also similar to the results of a study using a similar autobiographical recall task, again in a neurologically healthy sample (Rivers, Brackett, 
Reappraisal and discrete emotions in ABI

Katulak, \& Salovey, 2007). These findings suggest that reappraisal is an approach applied commonly to all negative emotions, for both HCs and individuals with brain injury, rather than suggesting that specific emotions have individual regulatory mechanisms.

The lack of significant difference between the ABI and HC group, however, is surprising, considering the numerous reports of specific emotional difficulties experienced by those with ABI (e.g. Fleminger, Oliver, Williams, \& Evans, 2003; Gainotti 1993; Shields et al., 2016). For example, the commonly reported mood disorders such as depression (Bombardier, Fann, Temkin, Esselman, et al., 2010) and anxiety (Mallya, Sutherland, Pongracic, Mainland, \& Ornstein, 2015), and difficulties with anger and aggression (Baguley, Cooper, \& Felmingham, 2006). There are a number of possibilities for this finding. Firstly, it is likely that emotional distress is a result of emotion dysregulation, which includes several strategies (Shields et al., 2016), whereas the present study focused exclusively on reappraisal. Additionally, during the task participants were instructed to reappraise, it does not follow that patients would spontaneously reappraise in real life.

\section{Reappraisal ability for positive emotion}

An unexpected finding was that of significantly lower reappraisal ability scores when up-regulating to positive emotion, suggesting that brain-injured patients find reappraisal comparatively less effective when attempting to increase neutral states. This is in line with the idea that the consequences and success of ER strategies are not always consistent across negative and positive emotions (Gross \& John, 2003; Gross \& Levenson, 1997; Nezlek \& Kuppens, 2008). This finding is especially interesting in the context of previous findings in non-brain-injured individuals, who find it easier to use reappraisal to regulate positive emotions, compared to negative emotions (Kim \& Hamann, 2007; Nezlek \& Kuppens, 2008; Ochsner, Ray, Cooper, Robertson, et al., 2004). It has been suggested that this may be 
Reappraisal and discrete emotions in ABI

because amplifying an emotional reaction is less difficult than decreasing it (Ochsner et al., 2004).

Notably, the opposite was found in the present study. There are a number of possibilities for this. Firstly, it may be related to how the conditions within the task differ. That is, for the down-regulation of negative emotions, participants first described a personal story which elicited a negative emotion. In contrast, the up-regulation of neutral to positive was framed as a neutral baseline, and therefore may require a different skill-set in which the ABI group were more impaired. This is in line with the idea that emotional intensity can affect ER strategy choice (Scheibe et al., 2015; Sheppes, Scheibe, Suri, \& Gross, 2011; Sheppes \& Gross, 2011).

A second possible explanation relates to reappraisal ability in those with low mood, who show decreased ability to sustain positive emotions when using reappraisal (Heller, Johnstone, Shackman, Light, et al., 2009). If the experience of positive emotion increases reappraisal use (Nezlek \& Kuppens, 2008; Fredrickson, 2001), then those who experience less positive affect may struggle to use reappraisal to up-regulate positive emotion. As there are high rates of depression among the ABI group, they may be subject to the same effects. However, re-investigation of our sample does not suggest that patients with lower mood are especially poor in up-regulation, as there was no correlation between their depression scores and reappraisal ability for the neutral condition (Spearman's rho $=.06, p=.736$ ). Future research would benefit from further investigating the effect of low mood in ABI on the upregulation of positive emotion.

These findings suggest that reappraisal modulates all negative emotions to a similar level (likely due to shared neural mechanisms) regardless of the specific negative emotion. However, for individuals with brain injury, reappraisal seems comparatively less effective when up-regulating neutral to positive emotion. 
Reappraisal and discrete emotions in ABI

\section{Cognitive bases of reappraisal}

In relation to the cognitive control hypothesis, the main finding was that working memory was the only significant predictor of both the average time taken to produce a reappraisal (reappraisal difficulty), and the total number of reappraisals produced (reappraisal productivity). This result provides additional support to previous findings in neurologically healthy participants that working memory is an important function for reappraisal (Hendricks \& Buchanan, 2015; Jasielska, Kaczmarek, Bronska, Dominiak et al., 2017; McRae et al., 2012; Schmeichel et al., 2008). Additionally, these findings extend a well-established association between working memory and both reappraisal ability (e.g. McRae et al., 2012), and frequency (e.g. Jasielska et al., 2017). Reappraisal is a complex cognitive process, that may well include several elements (McRae et al., 2012; Ochsner \& Gross, 2008). The present study especially supports the role of working memory in maintaining the goal of reappraising, and shielding it from the initial meaning that may otherwise remain in the forefront of attention (Kanske, Heisser, Schönfelder, Bongers \& Wessa, 2010; Gross, 2013).

A third finding of note was that none of the measures of cognitive control predicted reappraisal ability, the effectiveness of the reappraisal at modifying emotional intensity. This is surprising, because the majority of the literature has focused on this global ability, and the lack of significance might be argued to contradict the large body of neuroimaging studies demonstrating activation in brain areas associated with cognitive control (Buhle et al., 2014, for a review). However, these neuroimaging studies were in neurologically healthy individuals, who are able to reappraise effectively.

It is also possible that the lack of a significant predictor of effectiveness might be related to other components of cognitive control, not measured in the present study. For example, although somewhat unexplored, abstract reasoning may also be related to reappraisal (McRae et al., 2012; Salas et al., 2013). This is likely because reappraisal requires 
Reappraisal and discrete emotions in ABI

one to inhibit immediate emotional responses, in order to employ abstract ideas to change the meaning of a situation and its emotional impact (Salas et al., 2013).

\section{Models of Reappraisal}

How might these findings relate to existing models of reappraisal (e.g. Kalisch, 2009; Salas et al., 2014)? The present study appears to lend further support to a two-stage process, usually argued to consist of early and late components. The early stages are typically argued to involve choosing and implementing a reappraisal strategy, whereas the late components are concerned with maintaining the strategy in working memory (Kalisch, 2009). Developing this model further, Salas and colleagues (2014) suggested that inhibition and verbal fluency might be important for the early stages, inhibiting the initial meaning and generating a new appraisal, but they found no evidence for the role of working memory in this early phase. The present findings suggest that working memory appears to have a role in distancing from the negative initial appraisal, and producing a contesting mental representation of a positive nature. However, there may be an additional capacity required during the late phase, for example, to translate the reappraisal into a change in emotional intensity. It may also suggest that when it comes to regulating emotional experience of a mental representation, it is not so important whether cognitive control skills are average or limited, as long as one is able to generate a reappraisal.

\section{Implications for neuropsychological rehabilitation}

The present study contributes to our understanding of how brain injury may impact upon reappraisal, across various emotion classes. In particular, by demonstrating that patients with $\mathrm{ABI}$ are less able to generate reappraisals, and may find reappraisal less effective when up-regulating positive emotions. This is consistent with the idea that a brain injury increases one's vulnerability to emotion dysregulation (Salas et al., 2013; 2014), and perhaps especially 
Reappraisal and discrete emotions in ABI

for generating reappraisals, the experience of sustaining positive emotions, and avoiding instabilities (the 'mood swings' commonly reported by families).

The finding that patients find it difficult to generate reappraisals is particularly relevant for neuropsychological rehabilitation because this skill can be supported and facilitated externally, such as by family members. It has been shown that providing prompts can assist with the process of disengaging from the initial appraisal, and that can improve the capacity to generate alternative interpretations of events (Salas et al., 2013). It may also provide suggestions for treatment, through the development of programmes which include an element of reappraisal generation training.

Another core difficulty may be regulating the experience of positive emotions. One way to help promote and acknowledge positive affect is by looking to the field of Positive Psychology (PP) (Seligman, 2000; Seligman, Steen, Park, \& Peterson, 2005; See Donaldson, Dollwet, \& Rao, 2015 for a review), broadly, study of positive emotion and traits, well-being, and optimal functioning, and has developed a number of small, simple PP interventions (Seligman et al., 2005). Recently, there has been growing interest and appreciation of such interventions in rehabilitation (Bertisch, Rath, Long, Ashman, \& Rashid, 2014; Cullen, Pownall, Cummings, Baylan, et al., 2018; Evans, 2011; Karagiorgou, Evans, \& Cullen, 2017; Rabinowitz \& Arnett, 2018). One particularly influential approach is the "Three Good Things" diary, where one writes down three things that go well each day, for a week, with a short explanation about causality and each event (Seligman et al., 2005). PP has many light touch interventions, for example using signature strengths in a new way, savouring, and letters of gratitude (Boiler, Haverman, Westerhof, Riper, et al., 2013; Evans, 2011; Seligman et al., 2005).

An important point to address, however, is that many patients with ABI have executive impairment, and may find it difficult to implement such activities (Burgess, 
Reappraisal and discrete emotions in ABI

Alderman, Evans, Emslie, \& Wilson, 1998; Stuss, 2011; Stuss \& Alexander, 2007). This highlights the role of external regulation of emotion, which can be very effective (Salas 2012b; Salas et al., 2013). For instance, the use of scaffolding or external dialogue from a relative has been shown to compensate for cognitive impairment (Salas et al., 2013). One promising approach would be to reach relatives and care-givers to embed these ideas, so they can be consistently reinforced, and optimize generalisation of therapeutic gains. It might be that micro-interventions by families, such as scaffolding, and supporting patients to reflect on Three Good Things, could help patients acknowledge their positive emotions and stabilise the "mood swings".

\section{Future directions}

Calculating reappraisal ability in the ASRR task relied on self-report scores of emotional intensity. Though previous work has demonstrated that self-report measures during reappraisal correlate with changes in neural activation and physiology (Ochsner, Bunge, Gross, \& Gabrieli, 2002; Troy, Wilhelm, Shallcross, \& Mauss, 2010), some have reported dissociations between these measures (Mauss \& Robinson, 2009). Nonetheless, the subjective emotional experience is, in itself, an important component of ER processes. Future work may benefit from complementing the ASRR task with a measure peripheral physiology.

A further promising approach is the nature of the ASRR task itself, which has strong ecological validity. This follows an emerging trend in the study of emotion, where processes are observed or elicited in more naturalistic methods (Lench et al., 2011; Rovenpor, Skogsberg, \& Isaacowitz, 2013; Salas et al., 2012; 2015). As previously noted, personal events may be particularly effective at inducing higher levels of emotional arousal (Salas et al., 2012; 2015), and are closer to real-life situations, where reappraisal is an important part of daily life (Brockman, Ciarrochi, Parker, \& Kashdan, 2017; McRae et al., 2012). The 
ASRR allows for the investigation of reappraisal for various target emotions in a more naturalistic setting.

Much of the ER literature has investigated reappraisal, but there is growing interest in other regulatory processes: for example, situation selection (Markovitch, Netzer, \& Tamir, 2017; Sands \& Isaacowitz, 2017; Webb, Lindquist, Jones, Avishai, \& Sheeran, 2018) and attentional deployment (Demeyer, Sanchez, \& De Raedt, 2017; Ferri \& Hajcak, 2015; Wirth \& Kunzmann, 2018). Future work in people with neurological damage would benefit from better investigating these approaches, given that these strategies may be particularly important for those low in cognitive control, such as the elderly (Wirth \& Kunzmann, 2018) and people with mood disorders (Webb et al., 2018).

\section{Conclusion}

Emotional changes after brain injury have been the focus of a growing literature (Fleminger et al., 2003; Shields et al., 2016; Williams \& Evans, 2003). Indeed, with a greater understanding of the relevance of emotion in rehabilitation (Mateer, Sira, \& O'connell, 2005), we have seen a recent shift towards an approach which focuses upon socio-emotional adjustment (Bowen, Yeates, \& Palmer, 2010). Nonetheless, research on the effects of ABI on emotion regulation (based upon the 'process model') has been relatively modest (Salas et al., $2013 ; 2014)$. The present study not only demonstrates that an ABI can compromise the capacity to generate reappraisals, and in particular to do this rapidly, but this is the first study to demonstrate that brain-injured patients find reappraisal especially difficult for upregulating positive emotions. Consistent with previous research, the study also provides evidence in support of the role of working memory in reappraisal, which suggests a range of interventions which may be useful for clinicians and patients' families. 
Reappraisal and discrete emotions in ABI

\section{Acknowledgements}

This study was supported by EU Social Fund through the Welsh Government. We would like to thank all the participants and staff at the North Wales Brain Injury Service, Headway in North Wales, and the Headforward Centre. We would also like to thank the reviewers for their suggestions.

\section{References}

Adolphs, R. (2002). Neural systems for recognizing emotion. Current opinion in neurobiology, 12(2), 169-177.

Alway, Y., McKay, A., Ponsford, J., \& Schönberger, M. (2012). Expressed emotion and its relationship to anxiety and depression after traumatic brain injury. Neuropsychological rehabilitation, 22(3), 374-390.

Babbage, D. R., Yim, J., Zupan, B., Neumann, D., Tomita, M. R., \& Willer, B. (2011). Metaanalysis of facial affect recognition difficulties after traumatic brain injury. Neuropsychology, 25(3), 277.

Babyak, M. A. (2004). What you see may not be what you get: a brief, nontechnical introduction to overfitting in regression-type models. Psychosomatic medicine, 66(3), 411-421.

Baguley, I. J., Cooper, J., \& Felmingham, K. (2006). Aggressive behavior following traumatic brain injury: how common is common?. The Journal of head trauma rehabilitation, 21(1), 45-56

Bechara, A. (2004). Disturbances of emotion regulation after focal brain lesions. Int Rev Neurobiol, 62(159), 93. 
Reappraisal and discrete emotions in ABI

Beer, J. S., \& Lombardo, M. V. (2007). Insights into emotion regulation from neuropsychology. In J. J., Gross (Ed.), Handbook of emotion regulation, (pp. 69-86), New York: The Guilford Press.

Bertisch, H., Rath, J., Long, C., Ashman, T., \& Rashid, T. (2014). Positive psychology in rehabilitation medicine: A brief report. NeuroRehabilitation, 34(3), 573-585.

Bolier, L., Haverman, M., Westerhof, G. J., Riper, H., Smit, F., \& Bohlmeijer, E. (2013). Positive psychology interventions: a meta-analysis of randomized controlled studies. BMC public health, 13(1), 119.

Bombardier, C. H., Fann, J. R., Temkin, N. R., Esselman, P. C., Barber, J., \& Dikmen, S. S. (2010). Rates of major depressive disorder and clinical outcomes following traumatic brain injury. Jama, 303(19), 1938-1945.

Bornhofen, C., \& Mcdonald, S. (2008). Treating deficits in emotion perception following traumatic brain injury. Neuropsychological rehabilitation, 18(1), 22-44.

Bowen, C., Yeates, G., \& Palmer, S. (2010). A relational approach to rehabilitation: Thinking about relationships after brain injury. London: Karnac Books.

Brockman, R., Ciarrochi, J., Parker, P., \& Kashdan, T. (2017). Emotion regulation strategies in daily life: mindfulness, cognitive reappraisal and emotion suppression. Cognitive Behaviour Therapy, 46(2), 91-113.

Buhle, J. T., Silvers, J. A., Wager, T. D., Lopez, R., Onyemekwu, C., Kober, H., ... \& Ochsner, K. N. (2014). Cognitive reappraisal of emotion: a meta-analysis of human neuroimaging studies. Cerebral cortex, 24(11), 2981-2990.

Burgess, P. W., \& Shallice, T. (1997). The Hayling and Brixton Tests. Thurston, Suffolk: Thames Valley Test Company. 
Reappraisal and discrete emotions in ABI

Burgess, P. W., Alderman, N., Evans, J., Emslie, H., \& Wilson, B. A. (1998). The ecological validity of tests of executive function. Journal of the international neuropsychological society, 4(6), 547-558.

Calder, A. J., Keane, J., Manes, F., Antoun, N., \& Young, A. W. (2000). Impaired recognition and experience of disgust following brain injury. Nature neuroscience, 3(11), 1077.

Celeghin, A., Diano, M., Bagnis, A., Viola, M., \& Tamietto, M. (2017). Basic emotions in human neuroscience: neuroimaging and beyond. Frontiers in Psychology, 8, 1432. Chirico, A., Cipresso, P., \& Gaggioli, A. (2018). Psychophysiological Specificity of Four Basic Emotions Through Autobiographical Recall and Videos. In International Symposium on Pervasive Computing Paradigms for Mental Health (pp. 1-8). Springer, Cham.

Coetzer, B. R., Vaughan, F. L., Roberts, C. B., \& Rafal, R. (2003). The development of a holistic, community based neurorehabilitation service in a rural area. Journal of Cognitive Rehabilitation, 21(1), 4-15.

Croker, V., \& McDonald, S. (2005). Recognition of emotion from facial expression following traumatic brain injury. Brain Injury, 19(10), 787-799.

Cullen, B., Pownall, J., Cummings, J., Baylan, S., Broomfield, N., Haig, C., ... \& Evans, J. J. (2018). Positive PsychoTherapy in ABI Rehab (PoPsTAR): a pilot randomised controlled trial. Neuropsychological rehabilitation, 28(1), 17-33.

Davidson, R. J. (2001). Prefrontal and amygdala contributions to emotion and affective style. In G. Gainotti (Ed.), Emotional behaviour and its disorders Handbook of neuropsychology. (2 ${ }^{\text {nd }}$ ed., vol.5, pp.111-125). Amsterdam: Elsevier. 
Reappraisal and discrete emotions in ABI

Davis, E. L., Quiñones-Camacho, L. E., \& Buss, K. A. (2016). The effects of distraction and reappraisal on children's parasympathetic regulation of sadness and fear. Journal of experimental child psychology, 142, 344-358.

de Sousa, A., McDonald, S., \& Rushby, J. (2012). Changes in emotional empathy, affective responsivity, and behavior following severe traumatic brain injury. Journal of Clinical and Experimental Neuropsychology, 34(6), 606-623.

Delis, D. C., Kaplan, E., \& Kramer, J. H. (2001). Delis-Kaplan Executive function system: examiners manual. Psychological Corporation.

Demaree, H. A., Everhart, D. E., Youngstrom, E. A., \& Harrison, D. W. (2005). Brain lateralization of emotional processing: historical roots and a future incorporating “dominance". Behavioral and cognitive neuroscience reviews, 4(1), 3-20.

Demeyer, I., Sanchez, A., \& De Raedt, R. (2017). Older adults' attentional deployment: Differential gaze patterns for different negative mood states. Journal of behavior therapy and experimental psychiatry, 55, 49-56.

Diaz, A. P., Schwarzbold, M. L., Thais, M. E., Hohl, A., Bertotti, M. M., Schmoeller, R., ... \& Walz, R. (2012). Psychiatric disorders and health-related quality of life after severe traumatic brain injury: a prospective study. Journal of Neurotrauma, 29(6), 10291037.

Donaldson, S. I., Dollwet, M., \& Rao, M. A. (2015). Happiness, excellence, and optimal human functioning revisited: Examining the peer-reviewed literature linked to positive psychology. The Journal of Positive Psychology, 10(3), 185-195.

Draper, K., \& Ponsford, J. (2009). Long-term outcome following traumatic brain injury: a comparison of subjective reports by those injured and their relatives. Neuropsychological Rehabilitation, 19(5), 645-661.

Efron, B. (2003). Second thoughts on the bootstrap. Statistical Science, 18(2), 135-140. 
Reappraisal and discrete emotions in ABI

Ekman, P. (1992). An argument for basic emotions. Cognition \& emotion, 6(3-4), 169-200.

Etkin, A., Büchel, C., \& Gross, J. J. (2015). The neural bases of emotion regulation. Nature reviews neuroscience, 16(11), 693.

Evans, J. J. (2011). Positive psychology and brain injury rehabilitation. Brain Impairment, 12(2), 117-127.

Ferri, J., \& Hajcak, G. (2015). Neural mechanisms associated with reappraisal and attentional deployment. Current opinion in psychology, 3, 17-21.

Fleming, J., \& Strong, J. (1995). Self-awareness of deficits following acquired brain injury: Considerations for rehabilitation. British Journal of Occupational Therapy, 58(2), 5560.

Fleminger, S., Oliver, D. L., Williams, W. H., \& Evans, J. (2003). The neuropsychiatry of depression after brain injury. Neuropsychological Rehabilitation, 13(1-2), 65-87.

Fredrickson, B. L. (2001). The role of positive emotions in positive psychology: The broaden-and-build theory of positive emotions. American psychologist, 56(3), 218.

Gainotti, G. (1993). Emotional and psychosocial problems after brain injury. Neuropsychological rehabilitation, 3(3), 259-277.

Gainotti, G. (2005). Emotions, unconscious processes, and the right hemisphere. Neuropsychoanalysis, 7(1), 71-81.

Gainotti, G. (2012). Unconscious processing of emotions and the right hemisphere. Neuropsychologia, 50(2), 205-218.

Goldin, P. R., McRae, K., Ramel, W., \& Gross, J. J. (2008). The neural bases of emotion regulation: reappraisal and suppression of negative emotion. Biological psychiatry, 63(6), 577-586. 
Reappraisal and discrete emotions in ABI

Gomez Beldarrain, M. G., Garcia-Monco, J. C., Astigarraga, E., Gonzalez, A., \& Grafman, J. (2005). Only spontaneous counterfactual thinking is impaired in patients with prefrontal cortex lesions. Cognitive Brain Research, 24(3), 723-726.

Gratz, K. L., \& Roemer, L. (2004). Multidimensional assessment of emotion regulation and dysregulation: Development, factor structure, and initial validation of the difficulties in emotion regulation scale. Journal of psychopathology and behavioral assessment, 26(1), 41-54.

Gross, J. J. (2002). Emotion regulation: Affective, cognitive, and social consequences. Psychophysiology, 39(3), 281-291.

Gross, J. J. (2013). Emotion regulation: taking stock and moving forward. Emotion, 13(3), 359.

Gross, J. J. (2014). Emotion regulation: Conceptual and empirical foundations. In J. J. Gross (Ed.), Handbook of emotion regulation (pp.3-21). New York: Guilford Press.

Gross, J. J. (2015). Emotion regulation: Current status and future prospects. Psychological Inquiry, 26(1), 1-26.

Gross, J. J., \& John, O. P. (2003). Individual differences in two emotion regulation processes: implications for affect, relationships, and well-being. Journal of personality and social psychology, 85(2), 348.

Gross, J. J., \& Levenson, R. W. (1997). Hiding feelings: the acute effects of inhibiting negative and positive emotion. Journal of abnormal psychology, 106(1), 95.

Gross, J. J., \& Muñoz, R. F. (1995). Emotion regulation and mental health. Clinical psychology: Science and practice, 2(2), 151-164.

Gullone, E., \& Taffe, J. (2012). The Emotion Regulation Questionnaire for Children and Adolescents (ERQ-CA): A psychometric evaluation. Psychological assessment, 24(2), 409. 
Reappraisal and discrete emotions in ABI

Heller, A. S., Johnstone, T., Shackman, A. J., Light, S. N., Peterson, M. J., Kolden, G. G., ... \& Davidson, R. J. (2009). Reduced capacity to sustain positive emotion in major depression reflects diminished maintenance of fronto-striatal brain activation. Proceedings of the National Academy of Sciences, 106(52), 22445-22450.

Hendricks, M. A., \& Buchanan, T. W. (2016). Individual differences in cognitive control processes and their relationship to emotion regulation. Cognition and Emotion, 30(5), 912-924.

Henry, J. D., \& Crawford, J. R. (2004). A meta-analytic review of verbal fluency performance in patients with traumatic brain injury. Neuropsychology, 18(4), 621.

Jasielska, A., Kaczmarek, L., Brońska, A., Dominiak, M., Niemier, K., Patalas, D., ... \& Tomczak, M. (2017). The relationship between working memory and emotion regulation strategies. Roczniki Psychologiczne/Annals of Psychology, 18(4), 567-578.

Kalisch, R. (2009). The functional neuroanatomy of reappraisal: time matters. Neuroscience \& Biobehavioral Reviews, 33(8), 1215-1226.

Kanske, P., Heissler, J., Schönfelder, S., Bongers, A., \& Wessa, M. (2010). How to regulate emotion? Neural networks for reappraisal and distraction. Cerebral Cortex, 21(6), $1379-1388$.

Karagiorgou, O., Evans, J. J., \& Cullen, B. (2018). Post-traumatic growth in adult survivors of brain injury: a qualitative study of participants completing a pilot trial of brief positive psychotherapy. Disability and rehabilitation, 40(6), 655-659.

Kim, S. H., \& Hamann, S. (2007). Neural correlates of positive and negative emotion regulation. Journal of cognitive neuroscience, 19(5), 776-798.

Koole, S. L. (2009). The psychology of emotion regulation: An integrative review. Cognition and emotion, 23(1), 4-41. 
Reappraisal and discrete emotions in ABI

Kreutzer, J. S., Seel, R. T., \& Gourley, E. (2001). The prevalence and symptom rates of depression after traumatic brain injury: a comprehensive examination. Brain injury, 15(7), 563-576.

Lang, P. J., Bradley, M. M., \& Cuthbert, B. N. (1997). International affective picture system (IAPS): Technical manual and affective ratings. NIMH Center for the Study of Emotion and Attention, 1, 39-58.

Lazarus, R. S., \& Smith, C. A. (1988). Knowledge and appraisal in the cognition-emotion relationship. Cognition \& Emotion, 2(4), 281-300.

Lench, H. C., Flores, S. A., \& Bench, S. W. (2011). Discrete emotions predict changes in cognition, judgment, experience, behavior, and physiology: a meta-analysis of experimental emotion elicitations. Psychological bulletin, 137(5), 834.

Lench, H., \& Levine, L. (2005). Effects of fear on risk and control judgements and memory: Implications for health promotion messages. Cognition \& Emotion, 19(7), 1049-1069.

Lerner, J. S., \& Keltner, D. (2001). Fear, anger, and risk. Journal of personality and social psychology, 81(1), 146.

Lindquist, K. A., Wager, T. D., Kober, H., Bliss-Moreau, E., \& Barrett, L. F. (2012). The brain basis of emotion: a meta-analytic review. Behavioral and brain sciences, 35(3), 121-143.

Livingstone, K. M., \& Srivastava, S. (2012). Up-regulating positive emotions in everyday life: Strategies, individual differences, and associations with positive emotion and well-being. Journal of Research in Personality, 46(5), 504-516.

Luria, A. R. (1966). Higher cortical functions in man. London: Tavistock Publications.

Mak, A. K., Hu, Z. G., Zhang, J. X., Xiao, Z. W., \& Lee, T. M. (2009). Neural correlates of regulation of positive and negative emotions: an fMRI study. Neuroscience letters, 457(2), 101-106. 
Reappraisal and discrete emotions in ABI

Mallya, S., Sutherland, J., Pongracic, S., Mainland, B., \& Ornstein, T. J. (2015). The manifestation of anxiety disorders after traumatic brain injury: a review. Journal of neurotrauma, 32(7), 411-421.

Markovitch, N., Netzer, L., \& Tamir, M. (2017). What you like is what you try to get: Attitudes toward emotions and situation selection. Emotion, 17(4), 728.

Mateer, C. A., Sira, C. S., \& O'connell, M. E. (2005). Putting Humpty Dumpty together again: the importance of integrating cognitive and emotional interventions. The Journal of head trauma rehabilitation, 20(1), 62-75.

Mauss, I. B., \& Robinson, M. D. (2009). Measures of emotion: A review. Cognition and emotion, 23(2), 209-237.

Mauss, I. B., Levenson, R. W., McCarter, L., Wilhelm, F. H., \& Gross, J. J. (2005). The tie that binds? Coherence among emotion experience, behavior, and physiology. Emotion, 5(2), 175.

McDonald, S. (2017). Emotions are rising: The growing field of affect neuropsychology. Journal of the International Neuropsychological Society, 23(9-10), 719-731.

McDonald, S., Hunt, C., Henry, J. D., Dimoska, A., \& Bornhofen, C. (2010). Angry responses to emotional events: The role of impaired control and drive in people with severe traumatic brain injury. Journal of clinical and experimental neuropsychology, 32(8), 855-864.

McRae, K., Ciesielski, B., \& Gross, J. J. (2012b). Unpacking cognitive reappraisal: goals, tactics, and outcomes. Emotion, 12(2), 250.

McRae, K., Jacobs, S. E., Ray, R. D., John, O. P., \& Gross, J. J. (2012). Individual differences in reappraisal ability: Links to reappraisal frequency, well-being, and cognitive control. Journal of Research in Personality, 46(1), 2-7. 
Reappraisal and discrete emotions in ABI

Mikolajczak, M., Nelis, D., Hansenne, M., \& Quoidbach, J. (2008). If you can regulate sadness, you can probably regulate shame: Associations between trait emotional intelligence, emotion regulation and coping efficiency across discrete emotions. Personality and individual differences, 44(6), 1356-1368.

Millis, S. R., Rosenthal, M., Novack, T. A., Sherer, M., Nick, T. G., Kreutzer, J. S., ... \& Ricker, J. H. (2001). Long-term neuropsychological outcome after traumatic brain injury. The Journal of head trauma rehabilitation, 16(4), 343-355.

Neumann, D., Malec, J. F., \& Hammond, F. M. (2015). The association of negative attributions with irritation and anger after brain injury. Rehabilitation psychology, 60(2), 155.

Nezlek, J. B., \& Kuppens, P. (2008). Regulating positive and negative emotions in daily life. Journal of personality, 76(3), 561-580.

Ochsner, K. N., \& Gross, J. J. (2004). Thinking makes it so: A social cognitive neuroscience approach to emotion regulation. Handbook of self-regulation: Research, theory, and applications, 229-255.

Ochsner, K. N., \& Gross, J. J. (2005). The cognitive control of emotion. Trends in cognitive sciences, 9(5), 242-249.

Ochsner, K. N., \& Gross, J. J. (2008). Cognitive emotion regulation: Insights from social cognitive and affective neuroscience. Current directions in psychological science, $17(2), 153-158$.

Ochsner, K. N., Bunge, S. A., Gross, J. J., \& Gabrieli, J. D. (2002). Rethinking feelings: an FMRI study of the cognitive regulation of emotion. Journal of cognitive neuroscience, 14(8), 1215-1229. 
Ochsner, K. N., Ray, R. D., Cooper, J. C., Robertson, E. R., Chopra, S., Gabrieli, J. D., \& Gross, J. J. (2004). For better or for worse: neural systems supporting the cognitive down-and up-regulation of negative emotion. Neuroimage, 23(2), 483-499.

Odhuba, R. A., van den Broek, M. D., \& Johns, L. C. (2005). Ecological validity of measures of executive functioning. British Journal of Clinical Psychology, 44(2), 269-278.

Panksepp, J. (2003). At the interface of the affective, behavioral, and cognitive neurosciences: Decoding the emotional feelings of the brain. Brain and cognition, 52(1), 4-14.

Panksepp, J. (2004). Affective neuroscience: The foundations of human and animal emotions. Oxford university press.

Panksepp, J. (2005). Affective consciousness: Core emotional feelings in animals and humans. Consciousness and cognition, 14(1), 30-80.

Panksepp, J. (2011). The basic emotional circuits of mammalian brains: do animals have affective lives?. Neuroscience \& Biobehavioral Reviews, 35(9), 1791-1804.

Rivers, S. E., Brackett, M. A., Katulak, N. A., \& Salovey, P. (2007). Regulating anger and sadness: An exploration of discrete emotions in emotion regulation. Journal of Happiness Studies, 8(3), 393-427.

Rovenpor, D. R., Skogsberg, N. J., \& Isaacowitz, D. M. (2013). The choices we make: An examination of situation selection in younger and older adults. Psychology and aging, 28(2), 365 .

Salas Riquelme, C. E., Radovic, D., Castro, O., \& Turnbull, O. H. (2015). Internally and externally generated emotions in people with acquired brain injury: preservation of emotional experience after right hemisphere lesions. Frontiers in psychology, 6, 101. 
Salas Riquelme, C. E., Turnbull, O. H., \& Gross, J. J. (2014). Reappraisal generation after acquired brain damage: The role of laterality and cognitive control. Frontiers in psychology, 5, 242.

Salas, C. E., Gross, J. J., Rafal, R. D., Viñas-Guasch, N., \& Turnbull, O. H. (2013). Concrete behaviour and reappraisal deficits after a left frontal stroke: a case study. Neuropsychological rehabilitation, 23(4), 467-500.

Salas, C. E., Radovic, D., \& Turnbull, O. H. (2012). Inside-out: Comparing internally generated and externally generated basic emotions. Emotion, 12(3), 568.

Salibián-Barrera, M., Van Aelst, S., \& Willems, G. (2008). Fast and robust bootstrap. Statistical Methods and Applications, 17(1), 41-71.

Sands, M., \& Isaacowitz, D. M. (2017). Situation selection across adulthood: the role of arousal. Cognition and Emotion, 31(4), 791-798.

Scheibe, S., Sheppes, G., \& Staudinger, U. M. (2015). Distract or reappraise? Age-related differences in emotion-regulation choice. Emotion, 15(6), 677.

Schmeichel, B. J., Volokhov, R. N., \& Demaree, H. A. (2008). Working memory capacity and the self-regulation of emotional expression and experience. Journal of personality and social psychology, 95(6), 1526.

Schönberger, M., \& Ponsford, J. (2010). The factor structure of the Hospital Anxiety and Depression Scale in individuals with traumatic brain injury. Psychiatry research, 179(3), 342-349.

Seligman, M. E., \& Csikszentmihalyi, M. (2000). Positive psychology: An introduction (Vol. 55, No. 1, p. 5). American Psychological Association.

Seligman, M. E., Steen, T. A., Park, N., \& Peterson, C. (2005). Positive psychology progress: empirical validation of interventions. American psychologist, 60(5), 410. 
Reappraisal and discrete emotions in ABI

Sheppes, G., \& Gross, J. J. (2011). Is timing everything? Temporal considerations in emotion regulation. Personality and Social Psychology Review, 15(4), 319-331.

Sheppes, G., \& Meiran, N. (2007). Better late than never? On the dynamics of online regulation of sadness using distraction and cognitive reappraisal. Personality and Social Psychology Bulletin, 33(11), 1518-1532.

Sheppes, G., Scheibe, S., Suri, G., \& Gross, J. J. (2011). Emotion-regulation choice. Psychological science, 22(11), 1391-1396.

Shields, C., Ownsworth, T., O'Donovan, A., \& Fleming, J. (2016). A transdiagnostic investigation of emotional distress after traumatic brain injury. Neuropsychological rehabilitation, 26(3), 410-445.

Siedlecka, E., \& Denson, T. F. (2018). Experimental Methods for Inducing Basic Emotions: A Qualitative Review. Emotion Review, 1754073917749016.

Stanciu, M. A., Rafal, R. D., \& Turnbull, O. H. (2018). Preserved re-experience of discrete emotions: Amnesia and executive function. Journal of neuropsychology.

Stuss, D. T. (2011). Traumatic brain injury: relation to executive dysfunction and the frontal lobes. Current opinion in neurology, 24(6), 584-589.

Stuss, D. T., \& Alexander, M. P. (2007). Is there a dysexecutive syndrome?. Philosophical Transactions of the Royal Society B: Biological Sciences, 362(1481), 901-915.

Tracy, J. L., \& Randles, D. (2011). Four models of basic emotions: a review of Ekman and Cordaro, Izard, Levenson, and Panksepp and Watt. Emotion Review, 3(4), 397-405.

Troy, A. S., Shallcross, A. J., Brunner, A., Friedman, R., \& Jones, M. C. (2018). Cognitive reappraisal and acceptance: Effects on emotion, physiology, and perceived cognitive costs. Emotion, 18(1), 58. 
Reappraisal and discrete emotions in ABI

Troy, A. S., Wilhelm, F. H., Shallcross, A. J., \& Mauss, I. B. (2010). Seeing the silver lining: Cognitive reappraisal ability moderates the relationship between stress and depressive symptoms. Emotion, 10(6), 783.

Turnbull, O. H., Evans, C. E., \& Owen, V. (2005). Negative emotions and anosognosia. Cortex, 41(1), 67-75.

Vytal, K., \& Hamann, S. (2010). Neuroimaging support for discrete neural correlates of basic emotions: a voxel-based meta-analysis. Journal of cognitive neuroscience, 22(12), 2864-2885.

Webb, T. L., Lindquist, K. A., Jones, K., Avishai, A., \& Sheeran, P. (2018). Situation selection is a particularly effective emotion regulation strategy for people who need help regulating their emotions. Cognition and Emotion, 32(2), 231-248.

Wechsler, D. (2008). Wechsler Adult Intelligence Scale-Fourth Edition (WAIS-IV). San Antonio, TX: The Psychological Corporation.

Williams, W. H., \& Evans, J. J. (2003). Brain injury and emotion: An overview to a special issue on biopsychosocial approaches in neurorehabilitation. Neuropsychological rehabilitation, 13(1-2), 1-11.

Wirth, M., \& Kunzmann, U. (2018). Age differences in regulating negative emotions via attentional deployment. Psychology and aging, 33(3), 384.

Zigmond, A. S., \& Snaith, R. P. (1983). The hospital anxiety and depression scale. Acta psychiatrica scandinavica, 67(6), 361-370.

Zilverstand, A., Parvaz, M. A., \& Goldstein, R. Z. (2017). Neuroimaging cognitive reappraisal in clinical populations to define neural targets for enhancing emotion regulation. A systematic review. Neuroimage, 151, 105-116. 
Appendix 1 - Affective Story Recall Reappraisal Task Instructions

Introduction. The task was introduced as follows "Sometimes people try to make themselves feel better by looking on the bright side of things. You will see an emotion word on the screen, it will be either sad, scared, angry, or neutral. When you see each word, try to recall an event in your life that caused you to feel that emotion. Try to be very detailed about the way you feel. Following this, you will rate how intensely you feel that emotion now, upon describing the event, on a 0 to 10 scale, with 10 being most intense. The next step is to think of as many positive sides of that situation as you can, as quickly as you can. After thinking of the positive sides, rate how you feel again on the same 0 to 10 scale".

As the "neutral" condition involves the up-regulation of emotion from neutral to happy, this was explained in more detail: "With sad, scared, and angry, low scores on the scale mean less intensely and high scores mean more intense. However, with neutral, the more neutral it is, the lower the score, and high scores mean happy. Do you understand the difference?" Before we start we have time to practice".

Practice. Patients were then trained on the task using an "angry", and then a "neutral" practice condition, with examples of two stories: Having an argument for the "angry" condition, and watching television for the "neutral" condition. Following this, participants were shown the 0-10 scale, and the description of the scale was repeated again. They were then required to think of reappraisals when prompted by the written cue "Think of the positive sides. Try to be quick", before examples of possible reappraisals were provided. For the "neutral" condition the example reappraisals were "I was watching television with family, which I am lucky to have and spend time with" and "It was nice to have an evening to relax". The example reappraisals for the "angry" condition were: "We don't argue that often" and "Because of this we've talked about ways we can communicate better in future". The emotion intensity scale was shown and explained again. If the participant did not understand 
Reappraisal and discrete emotions in ABI

the task, the practice procedure was repeated, until the participant was satisfied that they understood what was required during the task.

Testing. Participants were informed that they have a maximum of three minutes to describe their stories (as per Salas et al., 2015), but they could use more time if needed. Their responses to the reappraising cue ("Think of the positive sides. Try to be quick") were timed and audio-recorded. These recordings are later transcribed verbatim. If participants struggled to think of stories, they were prompted with generic stories, for example "Some people would say they were sad when they lost a pet or family member", "Some people would say they were angry when they came across someone being rude or disrespectful", "Some would say they were scared when they feared for their or their family's safety or well-being", "Some would say they were neutral when going for a walk". Previous work using an ASR task, however, shows that brain-injured patients are able to recall emotional events (Salas et al., 2015, Turnbull et al., 2005). In line with this, all patients were able to recall stories, though some required additional prompting during the "neutral" condition, which consisted of asking the participant what they did on the days leading up to the testing session. 
Tables

Table 1. ABI participant information and injury characteristics.

\begin{tabular}{|c|c|c|c|c|c|c|}
\hline ID & Gender & Age & $\begin{array}{l}\text { Years in } \\
\text { education }\end{array}$ & Years since injury & Aetiology & Lesion location \& information \\
\hline 1 & M & 57 & 17 & 1 & CVA & $\begin{array}{l}\text { Left MCA territory. Including left } \\
\text { inferior frontal gyrus, white matter tracts } \\
\text { in left frontal lobes. }\end{array}$ \\
\hline 2 & M & 40 & 13 & 21 & TBI & Bilateral frontal contusions. \\
\hline 3 & M & 56 & 13 & 13 & TBI & -- \\
\hline 4 & M & 42 & 13 & 1 & TBI & $\begin{array}{l}\text { Left fronto-parietal SAH, left } \\
\text { intraparenchymal haematoma. Right } \\
\text { posterior parietal contusion. Right } \\
\text { temporal haematoma. Bilateral frontal } \\
\text { extra axial haemorrhage. }\end{array}$ \\
\hline 5 & M & 29 & 13 & 1 & TBI & $\begin{array}{l}\text { Bilateral frontal lobe contusion. Right } \\
\text { temporal lobe contusion. }\end{array}$ \\
\hline 6 & M & 55 & 16 & 7 & $\begin{array}{c}\text { Herpes Simplex } \\
\text { Encephalitis }\end{array}$ & $\begin{array}{l}\text { Bilateral asymmetric temporal lobe } \\
\text { involvement. }\end{array}$ \\
\hline 7 & $\mathrm{~F}$ & 56 & 18 & 1 & TBI & $\begin{array}{l}\text { Bilateral frontal intraparenchymal } \\
\text { haemorrhage, traumatic SAH, left } \\
\text { cerebellar haematoma extending to right } \\
\text { side. }\end{array}$ \\
\hline 8 & M & 57 & 16 & 22 & TBI & Right temporo-parietal lesion. \\
\hline 9 & M & 47 & 10 & 9 months & CVA & Multiple infarcts (bilateral). \\
\hline 10 & $\mathrm{~F}$ & 47 & 16 & 1 & TBI & $\begin{array}{l}\text { Traumatic SAH. Left frontal \& parietal } \\
\text { contusions. }\end{array}$ \\
\hline 11 & $\mathrm{~F}$ & 63 & 11 & 1 & CVA & Right MCA occlusion. \\
\hline 12 & M & 53 & 13 & 4 & TBI & $\begin{array}{l}\text { Left temporo-parietal compound skull } \\
\text { fracture with underlying contusion. }\end{array}$ \\
\hline 13 & M & 67 & 13 & 1 & $\begin{array}{c}\text { Hypoxic } \\
\text { Encephalopathy }\end{array}$ & 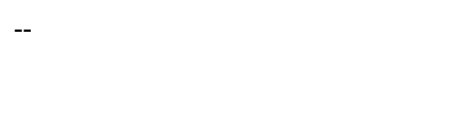 \\
\hline 14 & M & 55 & 10 & 10 months & CVA & Right PCA aneurysm. \\
\hline 15 & M & 47 & 13 & 29 & TBI & Left frontal and parietal lesions. \\
\hline
\end{tabular}




\begin{tabular}{|c|c|c|c|c|c|c|}
\hline 16 & $\mathrm{M}$ & 58 & 13 & 3 & CVA & $\begin{array}{l}\text { Extensive abnormal areas throughout } \\
\text { periventricular white matter. }\end{array}$ \\
\hline 17 & M & 58 & 13 & 5 & TBI & $\begin{array}{l}\text { Left frontal lobe lesion and possible } \\
\text { diffuse axonal injury. }\end{array}$ \\
\hline 18 & M & 53 & 13 & 9 months & CVA & Left frontal infarct. \\
\hline 19 & M & 54 & 11 & 1 & TBI & $\begin{array}{l}\text { Fracture of inferior floor of right orbital } \\
\text { wall. Presentation highly suggestive of } \\
\text { frontal lesion. }\end{array}$ \\
\hline 20 & M & 54 & 16 & 10 & CVA & Right MCA territory infarct. \\
\hline 21 & M & 50 & 13 & 32 & TBI & -- \\
\hline 22 & M & 45 & 16 & 1 & CVA & AcommA Aneurysm. \\
\hline 23 & M & 40 & 11 & 5 & CVA & AcommA Aneurysm. \\
\hline 24 & $\mathrm{~F}$ & 26 & 13 & 8 & TBI & Diffuse TBI -- \\
\hline 25 & M & 45 & 10 & 1 & TBI & $\begin{array}{l}\text { Right frontal lesion, left temporal } \\
\text { contusion. }\end{array}$ \\
\hline HF26 & $\mathrm{F}$ & 32 & 11 & 16 & Tumour/CVA & $\begin{array}{l}\text { Ruptured pituitary gland tumour. No } \\
\text { other information available. }\end{array}$ \\
\hline HF27 & M & 70 & 16 & 1 & CVA & $\begin{array}{l}\text { Bilateral multiple infarcts, temporal lobe } \\
\text { involvement. No other information } \\
\text { available. }\end{array}$ \\
\hline HF28 & M & 46 & 13 & 20 & TBI & Diffuse TBI, bilateral -- \\
\hline HF29 & M & 43 & 13 & 28 & TBI & Diffuse TBI-- \\
\hline HF30 & M & 59 & 11 & 24 & TBI & -- \\
\hline HW31 & $\mathrm{F}$ & 61 & 11 & 22 & TBI & Diffuse TBI-- \\
\hline HW32 & M & 34 & 16 & 1 & TBI & Right sided SAH. -- \\
\hline HW33 & M & 72 & 10 & 11 & TBI & -- \\
\hline HW34 & $\mathrm{F}$ & 34 & 16 & 10 & $\mathrm{AVM} / \mathrm{CVA}$ & Right parieto-occipital lesion. \\
\hline HW35 & M & 74 & 13 & 8 & CVA & Left-sided PCA territory. -- \\
\hline
\end{tabular}

$\overline{T B I}=$ traumatic brain injury; $C V A=$ cerebrovascular accident $;--=$ No information available; $A V M=$ arteriovenous malformation; $S A H=$ subarachnoid haemorrhage; $M C A=$ middle cerebral artery; $P C A=$ posterior cerebral artery; $A$ CommA = Anterior communicating artery. Participant IDs beginning with "HF" or "HW" were recruited through Headforward centre and Headway, respectively. 
Reappraisal and discrete emotions in ABI

Table 2. Emotional and cognitive functioning of $\mathrm{ABI}$ patients and $\mathrm{HC}$ participants

\begin{tabular}{|c|c|c|c|c|c|c|}
\hline & $\begin{array}{l}\text { Depression } \\
\text { (HADS) }\end{array}$ & $\begin{array}{l}\text { Anxiety } \\
\text { (HADS) }\end{array}$ & ERQ-CA & $\begin{array}{l}\text { Working memory } \\
\text { (Digit Span, } \\
\text { WAIS IV) }\end{array}$ & $\begin{array}{l}\text { Verbal ability } \\
\text { (Letter fluency, } \\
\text { DKEFS) }\end{array}$ & $\begin{array}{c}\text { Inhibition } \\
\text { (Hayling sentences) }\end{array}$ \\
\hline$M, S D(A B I)$ & $9.26,4.11$ & $9.89,4.32$ & $22.77,6.91$ & $22,5.79$ & $27.57,11.24$ & $15.03,3.88$ \\
\hline$M, S D(H C)$ & $3.32,2.40$ & $6.23,3.32$ & $31.32,6.74$ & $27.18,3.40$ & $32.32,7.89$ & $16.15,2.90$ \\
\hline$M, S D$ Scaled Score (ABI) & & & & $7.51,2.98$ & $7.03,3.43$ & $4.66,1.81$ \\
\hline$M$, SD Scaled Score $(H C)$ & & & & $10.14,2.08$ & $8.91,2.49$ & $5.14,1.29$ \\
\hline $\begin{array}{l}\text { Score range for "borderline } \\
\text { abnormal/impaired" }\end{array}$ & $8-10$ & $8-10$ & & $\begin{array}{c}6 \\
\text { (scaled) }\end{array}$ & $\begin{array}{c}4-6 \\
\text { (scaled) }\end{array}$ & $\begin{array}{c}3 \\
\text { (scaled) }\end{array}$ \\
\hline Score range for "clinical/impaired" & $11-21$ & $11-21$ & & $\begin{array}{c}1-5 \\
\text { (scaled) }\end{array}$ & $\begin{array}{c}1-3 \\
\text { (scaled) }\end{array}$ & $\begin{array}{c}1-2 \\
\text { (scaled) }\end{array}$ \\
\hline $\begin{array}{l}\text { Number participants }(/ 35) \text { in the } \\
\text { "borderline" range, "clinical/impaired" } \\
\text { range } \\
(\mathrm{ABI})\end{array}$ & 11,11 & 2,20 & & 3,10 & 12,4 & 3,4 \\
\hline $\begin{array}{l}\text { Number participants }(/ 22) \text { in the } \\
\text { "borderline" range, "clinical/impaired" } \\
\text { range } \\
\text { (HC) }\end{array}$ & 1,0 & 3,2 & & 0,1 & 1,0 & 3,0 \\
\hline $\begin{array}{l}\text { Significant difference } \\
\text { (t-test } p \text { value) }\end{array}$ & $<.001$ & .001 & $<.001$ & $<.001$ & .041 & .254 \\
\hline
\end{tabular}


Reappraisal and discrete emotions in ABI

Table 3. Time taken to generate a first reappraisal (reappraisal difficulty)

\begin{tabular}{ccccc}
\hline & Neutral & Sadness & Fear & Anger \\
\hline ABI Group & & & & \\
M, $S D$, Mdn & $8.96,4.38,8.00$ & $9.96,3.48,9.50$ & $7.79,3.18,8.50$ & $9.66,3.90,8.00$ \\
Mean Rank & 35.71 & 34.47 & 35.84 & 32.13 \\
& & & & \\
HC Group & & & & \\
M, SD, Mdn & $4.68,2.98,3.50$ & $6.59,3.52,5.25$ & $5.52,2.91,5.50$ & $7.32,3.60,8.00$ \\
Mean Rank & 18.32 & 20.30 & 18.11 & 24.02 \\
\hline
\end{tabular}

Table demonstrating descriptive statistics for reappraisal difficulty across all classes of emotion for ABI and HC groups. 
Reappraisal and discrete emotions in ABI

Table 4. Total number of reappraisals produced (Reappraisal productivity)

\begin{tabular}{|c|c|c|c|c|}
\hline & Neutral & Sadness & Fear & Anger \\
\hline \multicolumn{5}{|l|}{ ABI Group } \\
\hline$M, S D, M d n$ & $3.23,1.35,3.00$ & $3.31,2.06,3.00$ & $3.40,1.96,3.00$ & $3.09,1.82,3.00$ \\
\hline Mean Rank & 24.36 & 24.63 & 24.00 & 24.96 \\
\hline \multicolumn{5}{|l|}{ HC Group } \\
\hline$M, S D, M d n$ & $4.59,2.11,4.00$ & $4.73,2.10,4.00$ & $4.86,1.86,5.00$ & $3.23,1.35,3.00$ \\
\hline Mean Rank & 36.39 & 35.95 & 36.95 & 35.43 \\
\hline
\end{tabular}

Table demonstrating descriptive statistics for reappraisal productivity across all classes of emotion for ABI and HC groups. 
Reappraisal and discrete emotions in ABI

Table 5. Reappraisal ability scores (the difference in emotional intensity before, and after, reappraising

\begin{tabular}{ccccc}
\hline & Neutral & Sadness & Fear & Anger \\
\hline ABI Group & & & & \\
$M, S D$, Mdn & $1.08,1.18,0.50$ & $2.26,2.01,1.50$ & $2.40,1.98,2.50$ & $2.11,2.21,1.50$ \\
Mean Rank & 23.37 & 26.13 & 26.90 & 25.64 \\
HC Group & & & & \\
M, SD, Mdn & $3.21,2.65,2.75$ & $3.32,2.51,2.75$ & $3.59,3.09,2.50$ & $3.46,2.69,2.50$ \\
Mean Rank & 37.95 & 33.57 & 32.34 & 34.34
\end{tabular}

Table demonstrating descriptive statistics for reappraisal ability across all classes of emotion for ABI and HC groups. 
Reappraisal and discrete emotions in ABI

\section{Figures}

\section{Figure 1.}

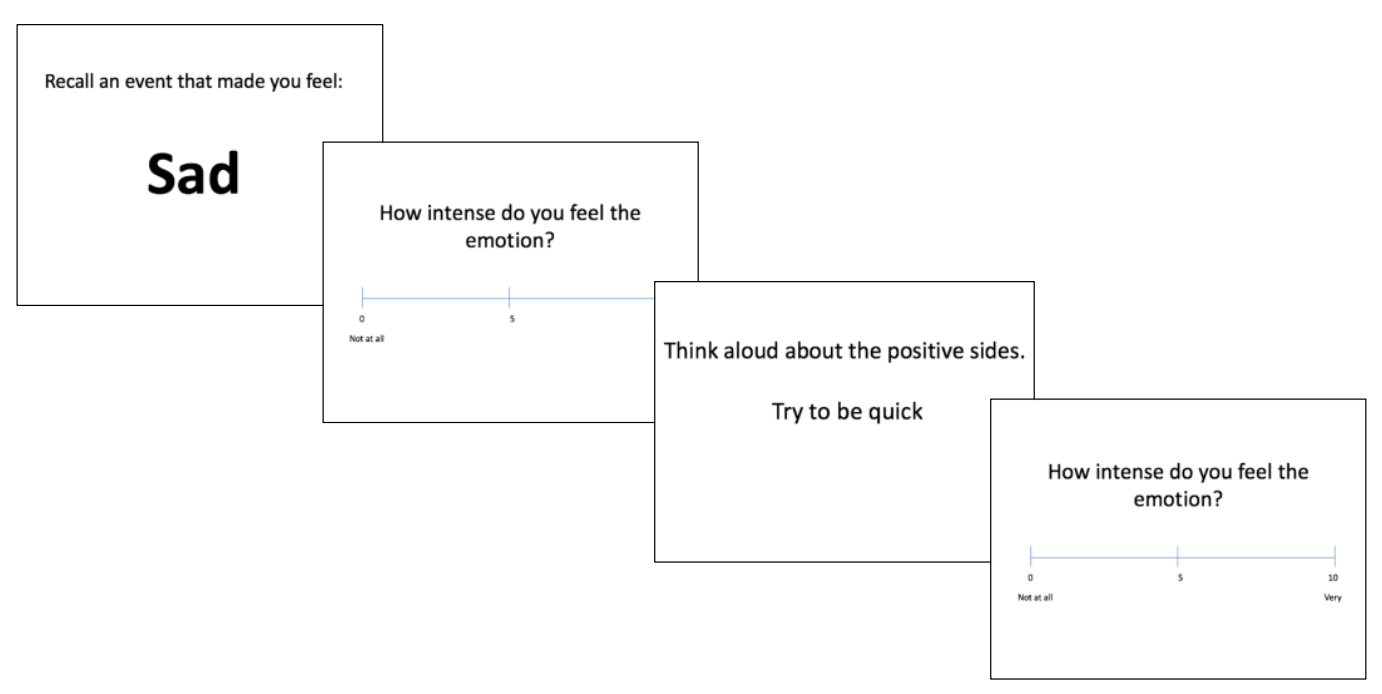

Figure 1. Figure demonstrating one trial in the ASRR task (sad condition). 
Reappraisal and discrete emotions in ABI

Figure 2.

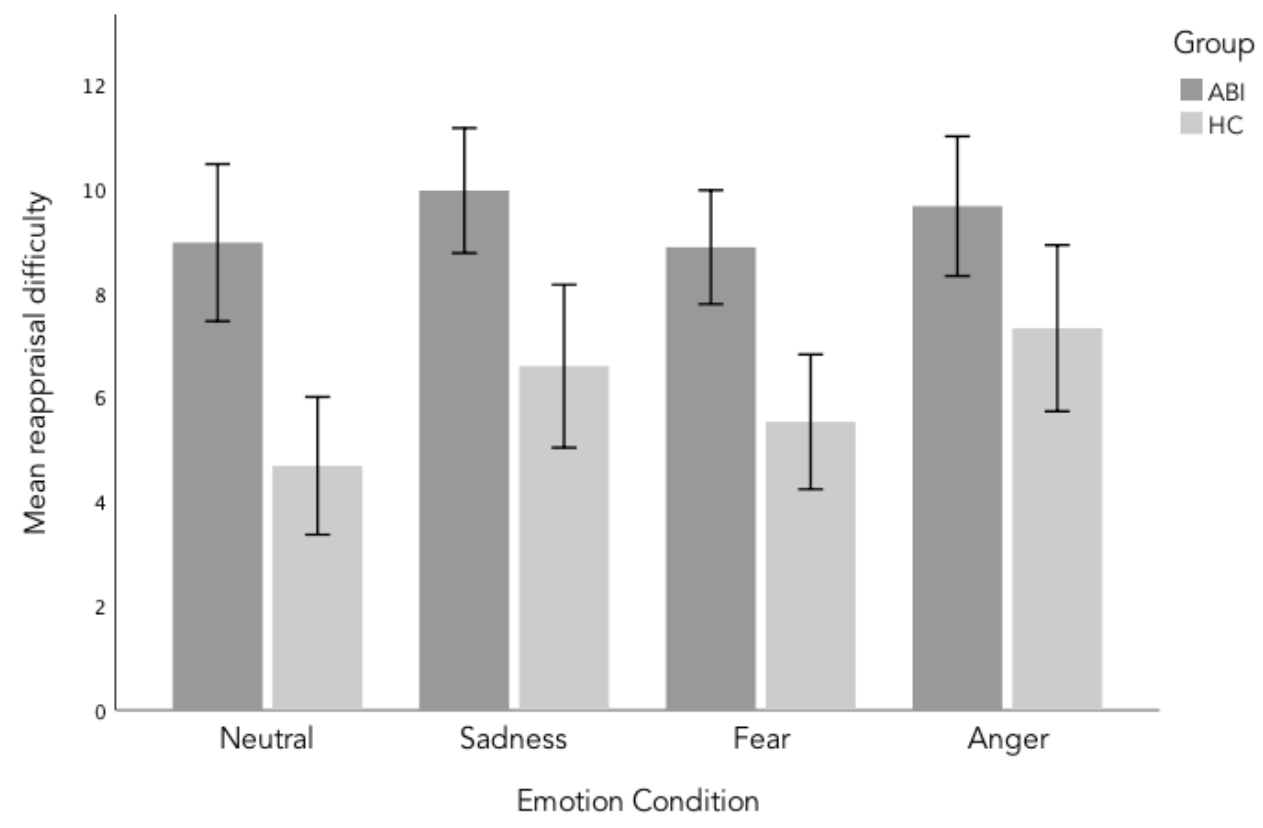

Figure 2. Bar chart representing the average time taken (seconds) (reappraisal difficulty) to generate a first reappraisal across all emotion conditions for both the ABI and HC group. 
Reappraisal and discrete emotions in ABI

\section{Figure 3.}

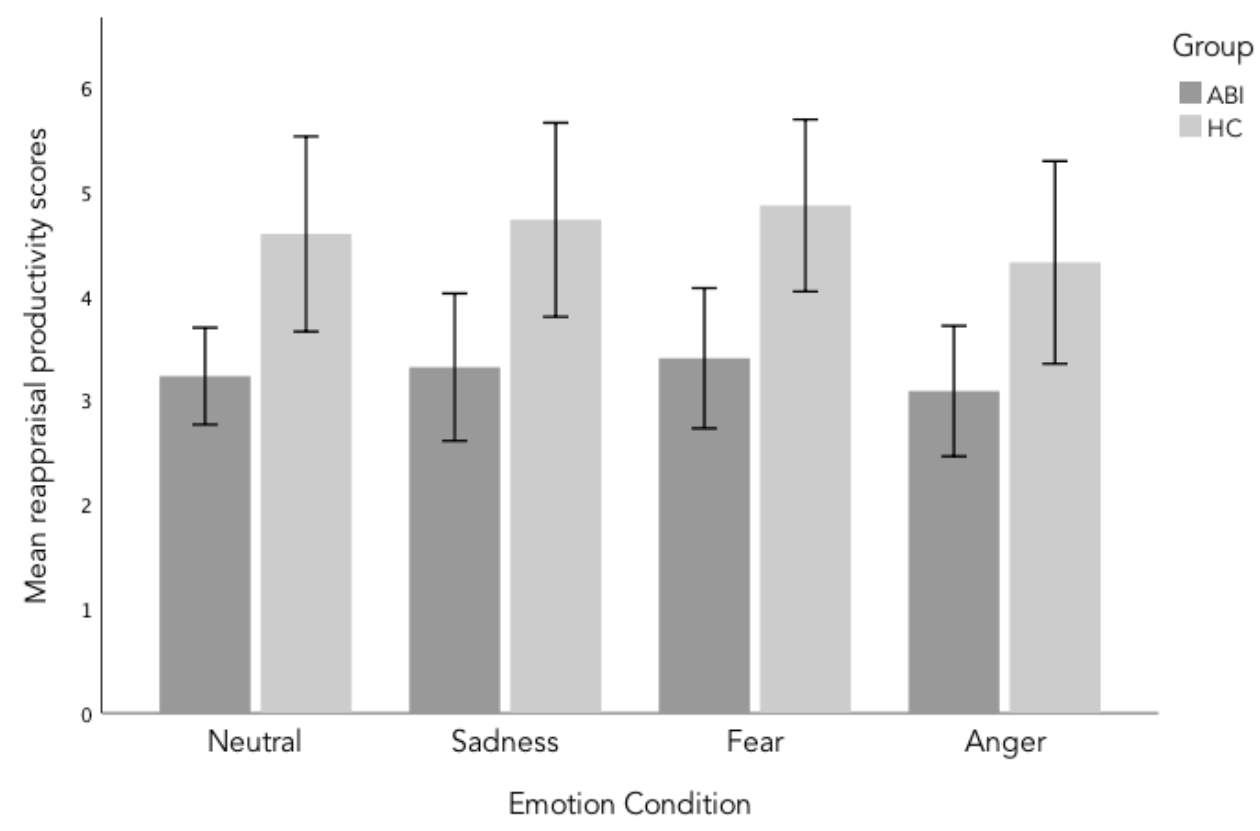

Figure 3. Bar chart representing the average number of reappraisals produced (reappraisal productivity) across all emotion conditions for both the ABI and HC group. 
Reappraisal and discrete emotions in ABI

\section{Figure 4.}

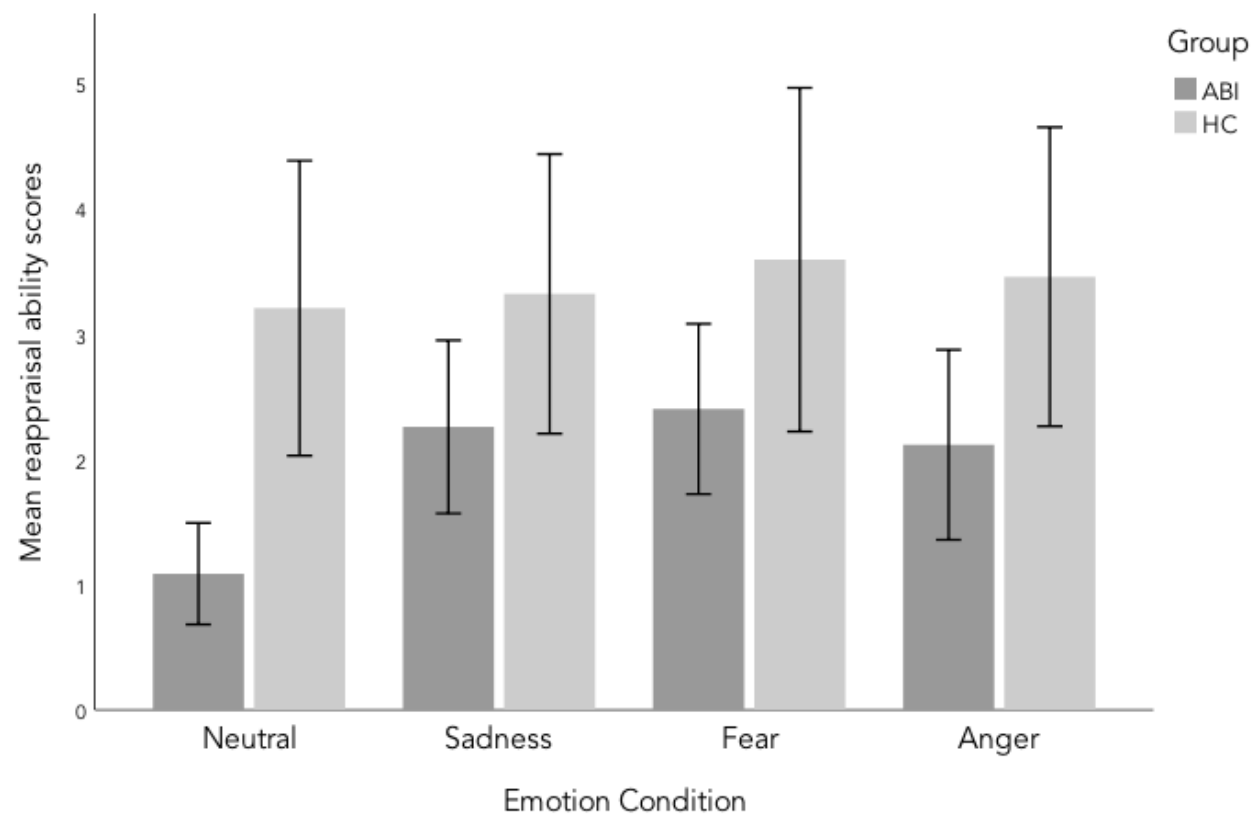

Figure 4. Bar chart representing the average difference in emotional intensity after reappraising (reappraisal ability) across all emotion conditions for both the ABI and HC group. 
Reappraisal and discrete emotions in ABI 